\title{
The effect of the natural degradation process on the cellulose structure of Moroccan hardwood fiber: a survey on spectroscopy and structural properties
}

\author{
Abdellatif Boukir ${ }^{1, *}$, Ikram Mehyaoui ${ }^{1}$, Somia Fellak ${ }^{1}$, Laurence Asia ${ }^{2}$ and Pierre Doumenq ${ }^{2}$ \\ ${ }^{1}$ Laboratory of Applied Chemistry, Faculty of Sciences and Techniques of Fez, Sidi Mohamed Ben \\ Abdellah University, B.P. 2202, Imouzzer road, Fez, Morocco \\ ${ }^{2}$ Laboratory of Environmental Chemistry, UMR CNRS 7376, MPO Team, Europôle Arbois BP 80, \\ 13545Aix in Provence Cedex 04; Aix-Marseille University, France
}

\begin{abstract}
The aim of this work is to study the effect of natural degradation on the cellulose structure conformation changes of 2 ageing Moroccan hardwoods (400 and 500 years) compared to recent one considered as a reference; and to provide information on the polymorphs content variability from two-phases material (crystalline and amorphous) influenced by a long time of ageing and environmental degradation effects. In order to investigate the effects of both natural degradation conditions and a long time of exposure on cellulose structure conformation (examined samples) with estimating their content (crystalline and amorphous cellulose), three combined techniques XRD, ATR-FTIR and FT-Raman spectroscopy were used. XRD results associated with the crystallographic planes and Miller indices provide information on the presence of a mixture of cellulose polymorphs (crystalline cellulose I, II, $\mathrm{I}_{\beta}$ and amorphous phase). The decrease in crystallinity-index values from recent to aged ones (38 to 19.5\%) confirms well the occurred alteration of crystalline cellulose fibres and their evolution towards a high content of the amorphous form. The prominent regression in the intensities of three FTIR fingerprint cellulose regions evolving towards an overall increase in the intensities of $\mathrm{C}=\mathrm{O}$ area (1733$1630 \mathrm{~cm}^{-1}$ ) is a sign on the introduced changes on cellulose conformation and cellulose fibres degradation more accentuated in the case of the very aged sample (500 years). Similar results were confirmed by combining FTRaman spectroscopy as a vibrational technique. No work has been done on this genus of degraded Moroccan hardwood and the relevance of this study is to investigate the compositional content and structural conformation, to determine the variability in the forms of both crystalline and amorphous cellulose phases with estimating the evolution of their polymorphism, and to monitor the degree of crystalline cellulose fibres deterioration.
\end{abstract}

Keywords: cellulose; crystallinity index and polymorphs; hardwood; X-ray diffraction (XRD); infra-red (ATRFTIR), Raman spectroscopy.

\section{Introduction}

Cellulose component is the most abundant and renewable biopolymer in nature biosynthesized largely in the cell wall and constitute the key material for the wood, paper, textile, lumber and renewable biofuel industries ${ }^{1}$. It is a linear polymer of D-anhydro glucopyranose units (AGU) linked by $\quad \beta-1,4$-glycosidic bonds. Two types of AGU units exist at the end of the cellulose chain; the reducing and non-reducing end, and the cellobiose represents the repeating unit. Also, the monomer units can form either highly ordered (crystalline) or less ordered (amorphous) structures, which is due to the result of extensive interaction through intra- and intermolecular

*Corresponding author: Abdellatif Boukir

Email address : aboukir@gmail.com

DOI : $\underline{\text { http://dx.doi.org/10.13171/mjc8319050801ab }}$ hydrogen bonding of the three hydroxyl groups present in each cellulose macromolecules ${ }^{2,3}$.

In nature, crystalline cellulose exists in four allomorphs: native cellulose I, cellulose II (prepared regeneration or alkaline treatment), cellulose III ( III $_{\mathrm{I}}$ and III $_{\mathrm{II}}$ forms) (prepared by liquid ammonia treatment) and cellulose IV.

These cellulose allomorphs are physically different, and they differ in reactivity. New evidence suggests that cellulose IV is a slightly disordered form of cellulose I $\beta$. Additionally, the native cellulose (crystalline fraction) presents a complex ultrastructure due to the presence of two forms for crystal phases; metastable triclinic $I_{\alpha}$ (one chain) and stable monoclinic $I_{\beta}$ (two chain) phase ${ }^{4}$. Generally, the cellulose $I_{\alpha}$ is the dominant form in algae and

Received January 22, 2019

Accepted March 23, 2019

Published May 8, 2019 
bacteria, while the cellulose $I_{\beta}$ is the dominant form in higher plants (wood and cotton) and tunicates. The main differences between the $I_{\alpha}$ and $I_{\beta}$ structures are in crystal packing, hydrogen bonding, conformations of the anhydroglucose residues and the $\beta-1,4$ linkages ${ }^{5}$. As reported by Bansal et al. ${ }^{6}$, the crystallographic structures and hydrogen bonding arrangements for cellulose $I_{\alpha}$ and cellulose $I_{\beta}$ provide important insights into cellulose stability and transformation and contribute toward a scientific basis for understanding cellulose bio-generation and reactivity. The relative amounts of celluloses $I_{\alpha}$ and $I_{\beta}$ vary with the source of the cellulose, with the $I_{\beta}$ form being dominant in higher plants ${ }^{7}$. It is in great importance to mention that the cellulose in its native state (cellulose I) has been reported to be more recalcitrant than its regenerated forms (cellulose II, III, etc) ${ }^{8,9}$.

The cellulosic wood materials have been used for the production of novel objects in several fields due to this unique and useful property of crystallinity, because of the crystalline fraction can provide mechanical rigidity and toughness for composite materials, and constitutes a source of the recalcitrance of lignocellulosic biomass against deconstructive processes ${ }^{10}$. Whatever, the effect of serious degradation of cellulose fraction can destroy the strong intermolecular bonding, resulting in a significant change in the chemical structure of cellulose compound as well as the decrease in its crystallinity. The loss of crystallinity amount results in an enhancement in properties of flexibility, dye sorption, moisture regain, swelling and chemical reactivity, whereas density, hardness, tensile strength and dimensional stability decrease ${ }^{11}$. Therefore, the determination of wood crystallinity may be an approach for understanding the effect of weathering on wood properties.

Numerous non-destructive methods as X-ray diffraction (XRD) ${ }^{10,12,13}$, attenuated total reflectanceFourier transform infrared spectroscopy (ATR-FTIR) spectroscopy ${ }^{14,15}$, Raman spectroscopy ${ }^{10}$, solid-state ${ }^{13} \mathrm{C}$ nuclear magnetic resonance ( $\left.\mathrm{NMR}{ }^{13} \mathrm{C} / \mathrm{CP}-\mathrm{MAS}\right)$ measurements 10 , and differential scanning calorimetry (DSC) ${ }^{13}$, were employed in several works to quantify the cellulose crystallinity and understand the structural roles of cellulose in the recalcitrant, mechanical and biological properties of plant cell walls. Lionetto et al. ${ }^{15}$, using X-ray diffraction and FTIR spectroscopy to quantify crystalline cellulose in lignocellulosic biomass, revealed that the crystallinity index (Cr.I.) of cellulose increased when wood was subjected to weathering accompanied by a considerable increase in the size of crystallites ${ }^{15}$. However, the presence of hemicellulose in lignocellulosic materials as softwoods and hardwoods reduced the crystallinity amount, whereas the syringyl lignin generated higher crystallinity ${ }^{16}$.
No work was meant to highlight the estimation of crystallinity feature and structural changes directly related to the cellulose fibers in Moroccan hardwood. Although, three non-destructive techniques incorporating ATR-FTIR, Raman and X-ray diffraction were employed in the present research to study cellulose polymer originated from argan Moroccan hardwood. Raman and Fourier transform infra-red (FTIR) spectroscopy technique for determining the crystalline absorption bands and functional groups interacting within the natural fiber and for investigating the effect of hydrogen bond on the cellulose fiber alteration. X-ray diffraction to quantify sample crystallinity based on calculated crystallinity index (Cr.I. \%) and crystalline size. These methods have been applied to reveal the modification in cellulose structure occurring after the natural degradation process. A good correlation between results obtained from ATR-FTIR, Raman and XRD was found. The experimental results proved that the proposed methods might be very useful tools for accurate estimation of the degradation level of wood exposed to weathering.

\section{Experimental}

\section{Materials}

The present study was conducted on three wooden materials about different centuries originated from the Agadir region. The dimensions of wood samples are $200 \times 200 \times 100 \mathrm{~mm}^{3}$ (tangential $\times$ radial $\times$ longitudinal directions). The three characterized samples are listed in Table 1.

Table 1. Description of wood Samples.

\begin{tabular}{|c|c|}
\hline Sample & Age \\
\hline $\mathrm{A}_{\mathrm{r}}$ & recent \\
\hline $\mathrm{A}_{4}$ & 4 centuries \\
\hline $\mathrm{A}_{5}$ & 5 centuries \\
\hline
\end{tabular}

\section{X-ray diffraction measurement}

The X-ray diffraction analysis was performed at room temperature with a X'Pert Pro diffractometer using $\mathrm{CuK} \alpha$ monochromatic wavelength radiation at $\lambda=1.5406 \AA$ and generator working at $40 \mathrm{kV}$ and 30 $\mathrm{mA}$. The angular scanning were measured in the area of $4^{\circ}<2 \theta<60^{\circ}$, it changes $0.016^{\circ}$ with a step of $40 \mathrm{~s}$. No background correction was made.

\section{Crystallinity index Cr.I}

The crystallinity index Cr.I. \% (sometimes called Segal index) ${ }^{17}$ of hardwood samples was calculated from diffraction intensity data using the following empirical equation (1) ${ }^{18,19,20,21,22}$ :

$\operatorname{Cr} . \mathrm{I}(\%)=\left(\frac{\mathrm{I}_{200}-\mathrm{I}_{\mathrm{am}}}{\mathrm{I}_{200}}\right) \times 100$ 
Where $\mathrm{I}_{200}$ is the total intensity of diffraction of the (200) lattice peak at a $2 \theta \sim 22.6^{\circ}$ for cellulose I (I $\beta)$ and of the (020) lattice peak for cellulose II at a $2 \theta \sim 21.6^{\circ}$, and $\mathrm{I}_{\mathrm{am}}$ is the intensity of diffraction of amorphous cellulose content at a $2 \theta \sim 18^{\circ}$ for cellulose I (I $\beta$ ) and at a $2 \theta \sim 16^{\circ}$ for cellulose II (minimum intensity in this region) ${ }^{18}$.

Crystalline size $\mathbf{D}_{(\mathrm{hkl})}$

The crystalline size $D_{(\mathrm{hkl})}$ was calculated by the Scherrer equation (2) ${ }^{23}$ perpendicularly to different lattice planes $\mathrm{D}_{(\mathrm{hkl})}$ from the 101, $1 \overline{1} 0,002$ and $004^{18,20,21,22,24}$.

$\mathrm{D}_{\mathrm{hkl}}=\mathrm{K} \times \lambda_{1} / \mathrm{B}_{\mathrm{hkl}} \mathrm{x} \cos \theta$

where $D_{(h k l)}$ is the crystalline size $(n m), k$ is Scherrer constant: correction factor $(0.89), \lambda_{1}$ is $\mathrm{X}$ ray wavelength $(1.5406 \AA), \mathrm{H}_{\mathrm{hkl}}$ is the angular full width at half maximum FWHM (sometimes called PWHM) in radians of the (hkl) line profile, and $\theta$ is the Bragg angle corresponding to the 200 plane.

\section{Attenuated total reflectance infrared spectroscopy (ATR-FTIR)}

Fourier Transform infrared (FTIR) transmission spectra were carried out through a BRUCKER VERTEX 70® spectrometer coupled to a Hyperion ${ }^{\circledR}$ microscope. All samples were scanned using Platinum diamond ATR (Attenuated Total Reflectance) in the wavenumber region between 4000 and $400 \mathrm{~cm}^{-1}$ with a resolution of $4 \mathrm{~cm}^{-1}$. At each position, 16 scans were averaged. The temperature and humidity room were controlled during analysis.

\section{FT-Raman Spectroscopy}

The FT-Raman study was conducted with a Bruker (USA) MultiRAM Stand Alone FT-Raman Spectrometer. The instrument is equipped with a diode-pumped Nd: YAG excitation source with a large emission intensity at $1.064 \mathrm{~nm}$. Furthermore, the signal was collected with a liquid nitrogen cooled germanium detector. For each FT-Raman measurement, 100 scans were averaged, with a resolution of $4 \mathrm{~cm}^{-1}$ and time measurement of 3 min for each spectrum. All FT-Raman spectra were registered from 4000 to $250 \mathrm{~cm}^{-1}$. Three analyses were performed on several locations for each sample.

\section{Results and Discussion}

\section{X-ray}

The cellulose of hardwood samples was analyzed by X-ray diffraction in order to determine both crystalline and amorphous phase as well as to estimate the amount of its crystalline fraction quantitatively. The XRD data from studied samples, over the $2 \theta$ range from $5^{\circ}$ to $60^{\circ}$, have been plotted in Fig. 1. This range is more reliable to cover all of the significant intensities from both crystalline and amorphous fraction of cellulose, while the peak located in the $2 \theta$ area ranging from $34.5^{\circ}$ to $35.2^{\circ}$ was reserved to a mixture of the crystalline fraction (cellulose I, II, I $\beta)^{20,21,25}$.

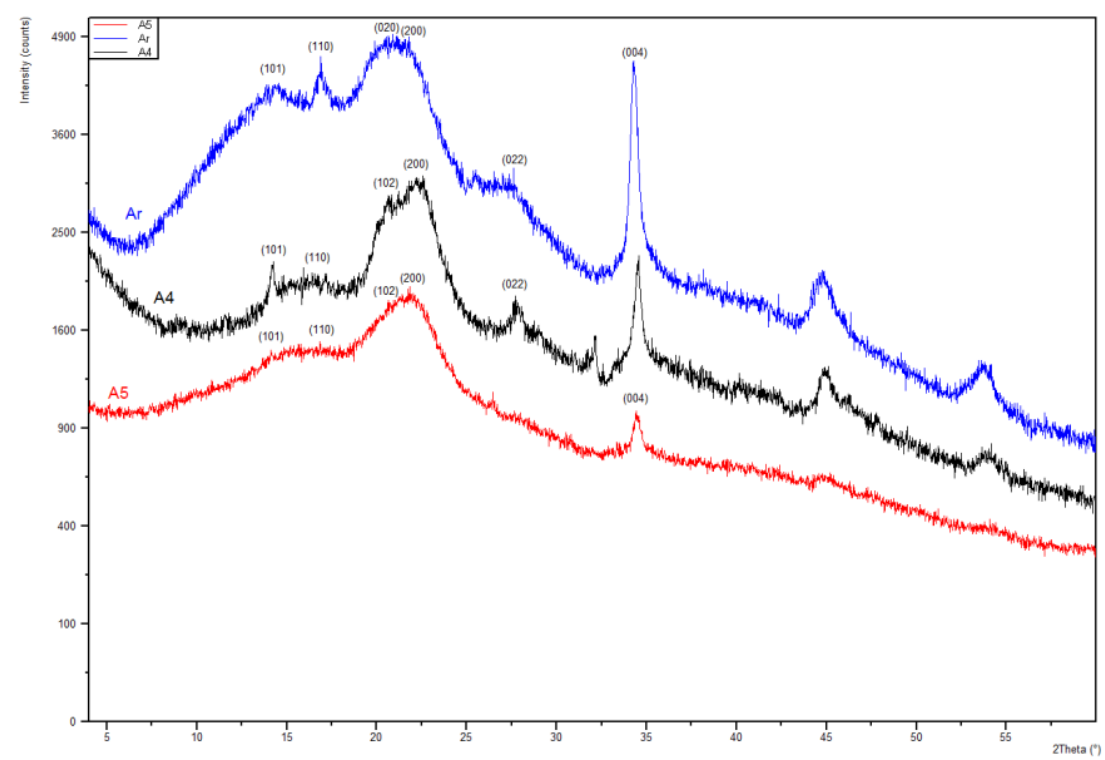

Figure 1. X-ray diffractogram of the hardwood samples

Compared to the XRD profile of cellulose from Eucalyptus spp. Fibres ${ }^{21}$ and others woods fibres such as Acacia ${ }^{26}$ and Argania Spinosa ${ }^{27}$, the recent wood profile (Fig. 1: $A_{r}$ ) manifested some differences with presenting an intense broad hump between $2 \theta$ of $10^{\circ}$ to $16^{\circ}$, a mixture of specific crystal sharp peak well resolved at $2 \theta$ of $16.5^{\circ}$
(Carrillo-Varela et al., $2018^{21}$ ) and an amorphous phase with a broad wide at the bottom $\left(2 \theta\right.$ of $16^{\circ}$ to $18^{\circ}$ ) (Nam et al., $2016^{20}$ ) closely neighboring and covering the left end of the great extent hump located between $2 \theta$ area $20^{\circ}$ and $25^{\circ}$. Moreover, we can note the high increase in the intensity of the 
sharp peak at $2 \theta$ of $34.5^{\circ}$ usually known by its very low intensity and characterize the crystalline phase.

Concerning the aged samples, a significant decrease in the intensities ( $2 \theta$ ranging from $10^{\circ}$ to $18^{\circ}$ and $34.5^{\circ}$ ) was observed from $\mathrm{A}_{\mathrm{r}}$ to $\mathrm{A}_{5}$, more pronounced in the case of $\left(\mathrm{A}_{4}\right)$. According to Ling et al., $2019^{22}$, in XRD feature the arising broad peaks instead of sharp ones, might be correlated to the contribution of small crystallite size which increases the breadth peak, or to the defects in the crystal lattice, and could be originated from the lacks of organization material responsible on the more diffusion in crystalline peaks.

Referring to past and recent literature data of French et Santiago Cintron $2013^{18}$, Nam et al. 2016 ${ }^{20}$, Ling et al. $2019^{22}$ and French $2014^{28}$, all our X-ray pattern samples showed similar characteristic peaks at $2 \theta$ of $14.5^{\circ}, 16.5^{\circ}, 21.6^{\circ}, 22.9^{\circ}$ and 34.5 corresponding to the (101), (110) and (020), (200) and (004) crystallographic planes, respectively $20,21,28$. The shoulder at $2 \theta=20.6^{\circ}$ that ascribes the (102) lattice plane reflection can also be observed. According to the literature data, these diffractions correspond to the typical profile of the cellulose I allomorph $7,21,28,29$. The trough peaks at $2 \theta=18$ between the 110 and the 200 crystallographic planes were assumed to account for the amorphous portion of cellulose ${ }^{20}$.

In XRD recent sample (Fig 1: $A_{r}$ ), the X-ray patterns indicated the presence of peaks related to a rich fraction of both cellulose I $\left(2 \theta: 14.5^{\circ}, 16.5^{\circ}\right.$, $22.9^{\circ}$ and $\left.34.5^{\circ}\right)^{21}$ and cellulose II $\left(2 \theta: 12^{\circ}, 20^{\circ}\right.$, $21.6^{\circ}$ and $\left.34.5^{\circ}\right)^{20,21}$. However, for the degraded sample, the decrease in the intensity of the peak at $22.9^{\circ}$ (cellulose I) towards the formation of the new very weak peak at $2 \theta$ of $12^{\circ}\left(\mathrm{A}_{4}\right)$ and two resolved humps in the $2 \theta$ area between $20^{\circ}$ and $23^{\circ}\left(\mathrm{A}_{4}, \mathrm{~A}_{5}\right)$ which resulting in arising shoulders, is an indication on their contribution to the content of cellulose II ${ }^{21}$.

The consistent fraction of cellulose II was manifested by the presence of four reflections at $2 \theta$ of $12^{\circ}, 20^{\circ}, 21.6^{\circ}$ attributed to the Miller indices of $(1 \overline{1} 0),(110)$ and $(020)$ respectively, and at $2 \theta$ of $34.5^{\circ}$ corresponding to the (004) crystallographic plane ${ }^{28}$. The results obtained are in accordance with the past and more recent literature findings of French et Santiago Cintron, $2013^{18}$, Nam et al., $2016^{20}$, Carrillo-Varela et al., $2018^{21}$, Ling et al. (2019) ${ }^{22}$ and French, $2014^{28}$. Recently and with careful XRD visual analysis, Edwards et al., $2018^{30}$, assigned the peaks in the form of a shoulder at about $2 \theta$ of $12^{\circ}$ accompanied by the peak at $2 \theta$ of $16.5^{\circ}$ to the very small cellulose II, and the convex intensity in the $2 \theta$ area of $15^{\circ}-17^{\circ}$ to a mixture of three celluloses: I ( $2 \theta$ area of $\left.15^{\circ}-17^{\circ}\right)$, II $\left(2 \theta\right.$ of $12^{\circ}$ and $2 \theta$ of $\left.16.5^{\circ}\right)$ and amorphous forms $\left(2 \theta\right.$ area of $\left.18^{\circ}\right)$. The assignment of the weak peak at $2 \theta: 12^{\circ}$ to cellulose II was supported by numerous recent literature studies ${ }^{20 \text {, }}$ 21,30

As presented in Fig. 1, from the recent sample $\left(A_{r}\right)$ to the oldest one $\left(A_{5}\right)$, all these peaks shifted to lower intensities suggesting the degradation of a crystalline form. Structural and chemical changes involved the crystalline and amorphous fraction of cellulose. Generally, amorphous cellulose is more susceptible (more reactive) than crystalline cellulose (stronger and less-reactive) to degradation process ${ }^{22}$, since it is more accessible to water, microorganisms 14,31. An unusual increase for the feature peak typical of (004) crystallographic plane at $34.52^{\circ}$ was manifested in the aged sample $\left(\mathrm{A}_{5}\right)$, generally presented by a very weak intensity peak. It indicates that a partial degraded cellulose might regenerate a native crystalline form and thus, contributing to the enrichment of the relative crystalline content upon time. Another proposition is that the crystalline structure cannot be destroyed, because decreasing elasticity due to higher thermal degradation causes a lack of sheer stress which destroys the hydrogen bonding of the crystalline structure, and consequently the increase in peak intensity related to crystalline cellulose fraction ${ }^{32}$.

The changes that might occur in these fractions upon exposure to the unfavorable environment and the effect of deterioration on microcrystalline structure were also investigated based on two calculated parameters: crystallinity index and crystallite seize. The obtained values of these parameters for studied samples are plotted in Table 2. It is worth to mention that the crystallinity index of cellulose $\mathrm{I}$ is given by comparing the minimum in intensity above baseline at $2 \theta=16.5^{\circ}\left(\mathrm{I}_{\mathrm{am}}\right)$, and the maximum in intensity at $2 \theta=22.9^{\circ}\left(\mathrm{I}_{200}\right)$, accounting for the amorphous part and the crystalline part (major diffraction from the 200 plane), respectively $6,28,20,21,22$. This parameter varies significantly depending on the choice of the measurement method. The crystallite sizes were calculated from 101, 110 and 002 lattice planes, respectively.

Table 2. Crystallite size and Crystallinity index values of cellulose from hardwood.

\begin{tabular}{|c|c|c|c|c|}
\hline Sample & $\begin{array}{c}\mathbf{D}(\mathbf{1 0 1}) \\
(\mathbf{n m})\end{array}$ & $\begin{array}{c}\mathbf{D}(\mathbf{1 1 0}) \\
(\mathbf{n m})\end{array}$ & $\begin{array}{c}\mathbf{D}(\mathbf{0 2 0}) \\
(\mathbf{n m})\end{array}$ & $\mathbf{C r . I}(\mathbf{\%})$ \\
\hline $\mathbf{A}_{\mathbf{r}}$ & - & 0.56 & 0.408 & 37.96 \\
\hline $\mathbf{A}_{\mathbf{4}}$ & 0.622 & - & 0.397 & 25.36 \\
\hline $\mathbf{A}_{\mathbf{5}}$ & 0.644 & - & 0.419 & 19.50 \\
\hline
\end{tabular}


It is shown that all amorphous cellulosic samples possessed a lower value of the crystallinity index. This can be referred to the sensibility of the analyzed sample to degradation and/or the presence of amorphous components as lignin and hemicelluloses that influence the estimation of crystallinity amount. It is reported in the literature that the presence of lignin lowers the crystallinity estimation by X-ray diffraction ${ }^{25}$.

The Cr.I index value was $37.96 \%$ for the nonaged sample $\mathrm{A}_{\mathrm{r}}$ and slightly decreased reaching $19.50 \%$ for the oldest sample $A_{5}$ (Table 2). This indicated that the crystalline region of cellulose fraction began to undergo chemical changes because of different natural degradation mechanisms as oxidation, hydrolysis. Also, the reduction of the crystalline amount of cellulose can refer to the destruction of hydrogen bonds in the crystalline cellulose fraction. The latter becomes small, and therefore, the cellulose microfibrils become harder and brittler efficiency causing efficient cut of hydrogen bonds, consequently, they become easy to destroy.

Generally, the crystalline cellulose structure is directly related to the hydrogen bonding between intermolecular hydroxyl groups and included water 33. Consequently, the loss of crystallinity is considered to result from opening of glucopyranose rings and destruction of their ordered packing ${ }^{34}$. These results are by literature data, suggesting that the rapid evaporation of water causes limits the chain mobility of cellulose, and consequently, its alignment, which decreases the crystallinity feature 35 . Thus, we can confirm that our samples underwent thermal degradation.

The small size differences may not be significant because of the calculations may have some uncertainties. So, the non-significant changes observed on $\mathrm{D}_{200}$ crystallite size (Table 2), mean that the microcrystalline structure was not significantly affected and broken by natural degradation process. Compared to the recent sample, the crystallite sizes of both $\mathrm{A}_{4}$ and $\mathrm{A}_{5}$ sample showed similar values (at around 0.644$)$ in the (101) and (020) planes, while no value was mentioned for their (110) direction planes. It means that the degradation affects a crystalline zone more than other and/or some of these zones degraded as faster than others. For the recent sample $A_{r}$, the crystallite size in (101) lattice plane could not be estimated due to the lower intensity of these peaks and to that the crystalline regions underwent degradation at a similar extent to the amorphous regions, thus the resulting materials showed no crystallites size. A mechanism of cellulose degradation in the natural environments proceeds through a depolymerisation step, involving the amorphous regions of cellulose, until the size of oligomers becomes sufficiently small to allow metabolisation by microorganisms or solubilisation by water ${ }^{25}$. Consequently, the reduction in crystallite size is correlated with the decrease in the crystalline mass fraction. It should be mentioned that the Segal crystallinity index can be influenced greatly by crystallite size ${ }^{36}$.

\section{FTIR spectroscopy}

The FTIR spectra of the three analyzed samples are reported in Fig. 2 and their assignments are summarized in Table 3.

As presented in Fig. 2, the strong and broad absorption band centred at $3330 \mathrm{~cm}^{-1}$ is generally characteristic of the mixture of both crystalline fractions $I_{\beta}$ and $I_{\alpha}{ }^{22,37-39}$ and assigned to O5$\mathrm{H} 5 \cdots \mathrm{O} 3$ intramolecular hydrogen bonds in carbohydrates (cellulose crystals) ${ }^{19,37,38}$. A mixture of intra- and intermolecular hydrogen bonds in cellulose are detected in the region between 3500 and $3000 \mathrm{~cm}^{-1}$. Concerning the crystalline form of cellulose, the monoclinic cellulose $I_{\beta}$ was identified by the slight peak at $3278 \mathrm{~cm}^{-122,27,39,40}$ related to

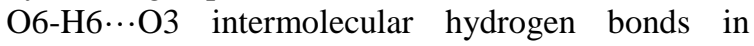
carbohydrates, while in triclinic $I_{\alpha}$ cellulose this band was detected at $3240 \mathrm{~cm}^{-122,27,40}$. According to Popescu et al. $2016^{38}$, the $\mathrm{O}-\mathrm{H}$ intramolecular hydrogen bonds of phenolic lignin appear at 3553 $\mathrm{cm}^{-1}$. Additionally, there are significant contributions from adsorbed water (weak absorption) arising from 1640 to $1620 \mathrm{~cm}^{-1}$ in the amorphous region of the sample $14,19,27,37,38,41$ and at $3553 \mathrm{~cm}^{-1}$ when it is weakly bonded ${ }^{38}$. A noticeable decrease in the intensities of these bands with increasing time was observed in Fig. 2. It indicates effectively the water desorption phenomenon followed by the decrease in the hydrogen bond strength between the cellulosic chains, leading to the destruction of crystalline cellulose structure. Recently, Broda et Popescu 2019 ${ }^{41}$ reported that the decrease in temperature reinforce the hydrogen bonds in the crystalline cellulose and microfibrils become harder and present a brittler efficiency. 


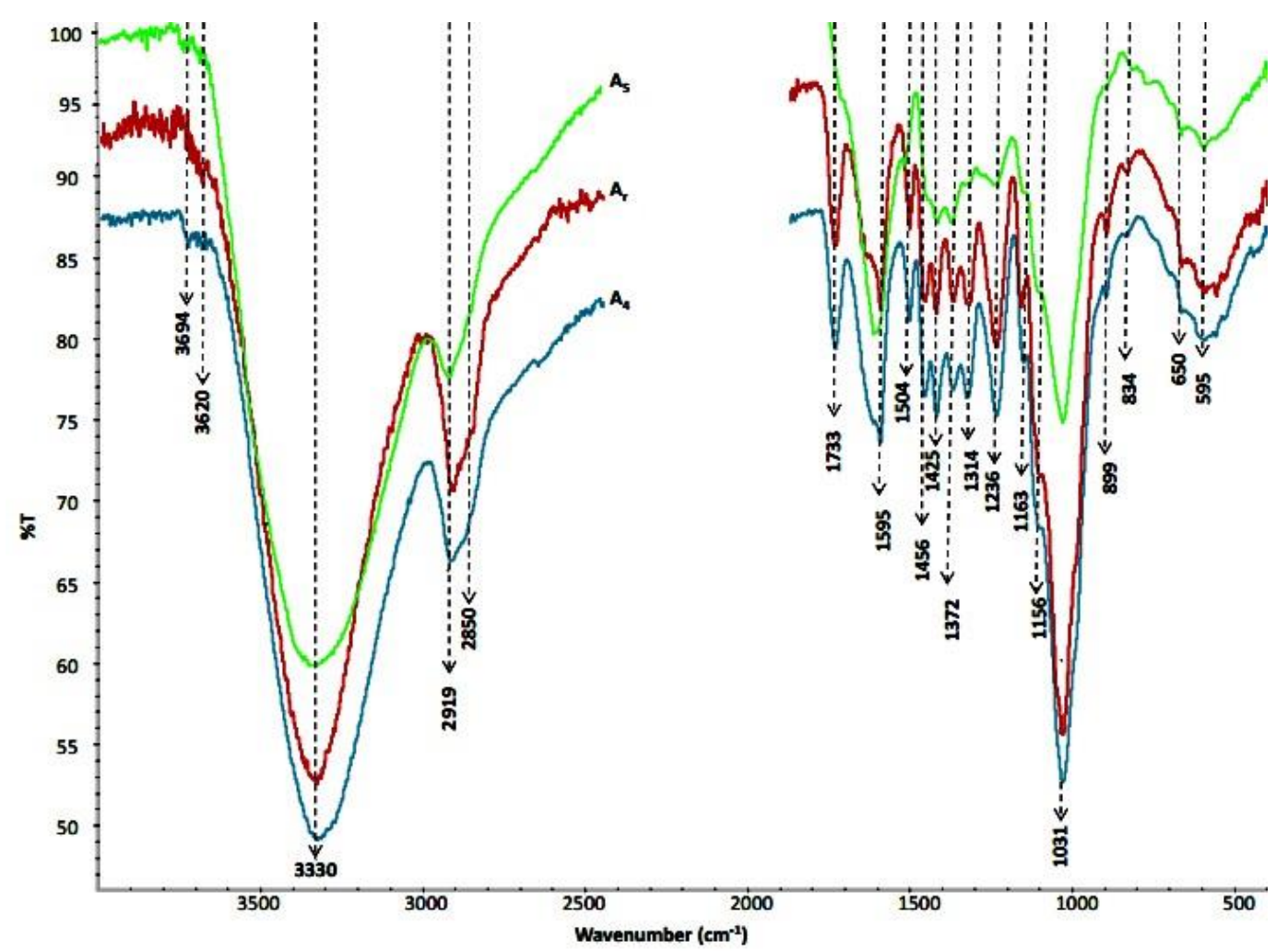

Figure 2. FTIR spectra $4000-500 \mathrm{~cm}^{-1}$ range acquired from hardwood samples.

Also, the cellulose of wood spectra typically shows multiple $\mathrm{C}-\mathrm{H}\left(\mathrm{sp}^{3}\right)$ stretching vibrations at 2850 that assigned to $v_{s} \mathrm{CH}_{2}$ and $2919 \mathrm{~cm}^{-1}$ ascribed to $v_{a s} \mathrm{CH}_{2}$ and $v \mathrm{C}-\mathrm{H}$ in cellulose, and to $v_{s} \mathrm{CH}_{3}$ (methoxyl group) in lignin ${ }^{19,22,37,38}$. Recently, Ling et al. $2019^{22}$ attributed the signal at $2944 \mathrm{~cm}^{-1}$ to cellulose $I_{\beta}$ accompanied with a shoulder at 2968 $\mathrm{cm}^{-1}$. As shown in Fig. 2, each FTIR spectrum presents the main characteristic peaks related to the mixture of crystallized and amorphous cellulose fractions. The presence of crystalline cellulose is confirmed by the three following signals at $1456 \mathrm{~cm}^{-}$ $127,37,39,42,1372 \mathrm{~cm}^{-1} 19,22,42-44$ and $1314 \mathrm{~cm}^{-1} 19,22,27,37-$ 41,44 (bending mode vibration of $\mathrm{C}-\mathrm{H}$ ), while the amorphous content is justified by the presence of centered peak at $1425 \mathrm{~cm}^{-1}$ corresponding to $\delta \mathrm{CH}_{2}$ bending vibration (scissoring) 16,19,27,39,40,43. According to Song et al. $2015^{42}$ and Zghari et al. $2018^{37}$ the crystalline cellulose I and cellulose II appear as doublet peak at $1430 \mathrm{~cm}^{-1}$ (strong band) and at $1420 \mathrm{~cm}^{-1}$ (weak band), respectively ${ }^{44}$. Furthermore, Hajji et al. $2015^{19}$ and Broda et al. $2019^{41}$ report that the decline in the intensities of the two bands at 1314 and $1163 \mathrm{~cm}^{-1}$ is correlated to the decrease of cellulose crystallinity (cellulose I). Usually in amorphous cellulose (disordered structure), these bands were located at 1336 and $1156 \mathrm{~cm}^{-1}$, respectively.

The two absorptions bands at 1163 and $1156 \mathrm{~cm}^{-}$ 1 are related to the crystalline and amorphous form of cellulose, respectively, characteristics of the C-O-C asymmetric bridge stretching vibration of the glycosidic ring. According to a recent study by Ling et al. $2019^{22}$, the introduced transformation of the two bands is considered as a key of included changes on fingerprint cellulose area, informing well on both distortions of crystalline arrangements and smaller crystallinity index. Similar spectral changes have been observed in our case study from recent sample $A_{r}$ to aged ones $\left(A_{4}\right.$ and $\left.A_{5}\right)$ indicating the conversion of crystalline content towards an amorphous fraction. This finding supports the hypothesis of distortion in cellulose crystalline arrangements. The fingerprint region of cellulose with prominent signal centred at $1031 \mathrm{~cm}^{-1}(\mathrm{C}-\mathrm{O})$ is gradually shifted to the lower intensity from recent to altered sample $\mathrm{A}_{5}$. Additionally, the visible and notable reduction indicate well the occurred changes in the structural conformation of the aged cellulose sample $\left(A_{5}\right)$ which is more affected after 500 years of exposure to natural environmental degradation process.

Concerning the band at $899 \mathrm{~cm}^{-1}$ ascribed to C-O-C stretching vibration mode of cellulose $\beta$-(14)-glycosidic linkage is related to the content of amorphous cellulose which is completely in accordance with published literature studies $16,19,22,38,39,43$. However, this band is sensitive to changes, and so, a portion of amorphous cellulose content underwent crystallization due to mechanochemical processes ${ }^{22}$ and/or to natural environmental degradation conditions ${ }^{37,42,44}$, that is why it is subject of many controversies data $22,37,42,44$. A clear indications have been reported by Song et al. $2015^{42}$ which attributed the weak and broad absorption band to cellulose I, while the strong and 
sharp one might be assigned to cellulose II and amorphous cellulose. The similar finding was confirmed by Hajji et al. $2016^{44}$ and Zghari et al. $2018^{37}$ which reported that the ageing process promote the breakage of the $\mathrm{C}-\mathrm{O}-\mathrm{C}$ bonds of crystalline cellulose $\mathrm{I}$ in the $\beta$-(1-4)-glycosidic linkage.

In recent literature data, Ling et al. $2019^{22}$ correlated the weak signal at $720 \mathrm{~cm}^{-1}$ to the presence of a small amount of cellulose $I_{\beta}$ and ascribed it to $\mathrm{CH}_{2}$ rocking vibration ${ }^{37,40}$, while the tiny peak at $750 \mathrm{~cm}^{-1}$ attributed to a small amount of cellulose $I_{\alpha}$, the latter is supported by the presence of $\mathrm{O}-\mathrm{H}$ stretching vibration mode at $3240 \mathrm{~cm}^{-122,40}$.

The FTIR crystalline and amorphous results correlate well with the crystallinity index values measured in XRD section (X-ray diffraction, Table 2).

Table 3. Assignments of the main vibrations of cellulose in the hardwood FTIR spectra.

\begin{tabular}{|c|c|c|c|}
\hline Wavenumber $\left(\mathrm{cm}^{-1}\right)$ & Assignment & Cellulose fraction & Reference \\
\hline 3330 & $\begin{array}{l}\mathrm{v}(\mathrm{OH}) \text { stretching vibration of alcohol- } \\
\text { bonded hydroxyl groups }\end{array}$ & crystalline $I_{\beta}+\mathrm{I} \alpha$ & $22,38,39,37$ \\
\hline 3278 & O6 H6 $\cdots \mathrm{O} 3$ intermolecular hydrogen bonds & cellulose $I_{\beta}$ & $22,27,39,40$ \\
\hline $3000-2850$ & $\begin{array}{c}v_{a s} \mathrm{CH}_{2} \text { and } v_{s} \mathrm{CH}_{2} \text { in methylene and } \\
v_{a s} \mathrm{CH}_{3}, v_{s} \mathrm{CH}_{3} \text { in methyl groups }\end{array}$ & $\begin{array}{l}\text { crystalline and } \\
\text { amorphous }\end{array}$ & $39,40,44$ \\
\hline 2900 & $\mathrm{vC}-\mathrm{H}$ stretching vibration & crystalline & $22,39,43$ \\
\hline 1456 & $\begin{array}{c}\delta \mathrm{CH}_{2} \text { asymmetric bending mode } \\
\text { (scissoring) }\end{array}$ & crystalline & $27,37,39,42$ \\
\hline 1425 & $\begin{array}{c}\delta \mathrm{CH}_{2} \text { symmetric bending (scissoring) } \\
\text { crystalline cellulose I at } 1430 \mathrm{~cm}^{-1} \text { (strong) } \\
39,43 \text { and crystalline cellulose II at } 1420 \mathrm{~cm}^{-1} \\
\text { (weak) } \\
\text { O-C-H in plane bending vibration } \\
37,42\end{array}$ & amorphous & $\begin{array}{c}42,43,19,37 \\
39,40,27 \\
16\end{array}$ \\
\hline 1372 & $\delta \mathrm{C}-\mathrm{H}$ bending vibration & crystalline & $\begin{array}{l}22,42,43,44, \\
19,37,39,27\end{array}$ \\
\hline 1314 & $\delta \mathrm{CH}_{2}$ rocking ${ }^{40}$ & crystalline & $\begin{array}{l}22,27,19,37 \\
40,38,39,44\end{array}$ \\
\hline 1163 & \multirow[t]{2}{*}{$\begin{array}{c}\text { C-O-C asymmetric bridge stretching } \\
\text { vibration }\end{array}$} & crystalline & $\begin{array}{c}22,37,38,40 \\
27,43\end{array}$ \\
\hline 1156 & & moreover, amorphous & \\
\hline 1110 & $\begin{array}{c}\text { C-O-H anti-asymmetric in-plane stretching } \\
\text { vibrations }\end{array}$ & $\begin{array}{l}\text { crystalline and } \\
\text { amorphous }\end{array}$ & $22,37,39,43$ \\
\hline 899 & $\begin{array}{c}v \mathrm{C}_{1}-\mathrm{O}-\mathrm{C} \text { of } \beta-(1-4) \text {-glycosidic linkage bond } \\
\text { (weak and broad in cellulose I, but strong } \\
\text { and sharp in cellulose II and amorphous } \\
\text { cellulose) }{ }^{37,42} \text { and references cited }\end{array}$ & $\begin{array}{l}\text { amorphous } \\
+ \\
\text { (a portion of this band } \\
\text { is sensitive to change } \\
\text { and might undergo } \\
\text { crystallization) }\end{array}$ & $\begin{array}{c}16,19,22,27 \\
37,38,43\end{array}$ \\
\hline 720 & $\begin{array}{l}\mathrm{CH}_{2} \text { rocking vibration in cellulose } I_{\beta} \\
\text { (cellulose } \mathrm{I} \alpha \text { appear generally as a tiny peak } \\
\text { at } 750 \mathrm{~cm}^{-1} \text { and } 3240 \mathrm{~cm}^{-1} 22,37,40 \text { ) }\end{array}$ & $\begin{array}{l}\text { a small amount of } \\
\text { cellulose } I_{\beta}\end{array}$ & $22,27,37,40$ \\
\hline 650 & $\begin{array}{c}\delta \mathrm{O}-\mathrm{H}_{\mathrm{oop}} \text { out of plane bending mode (weak } \\
\text { and broad band) }\end{array}$ & cellulose crystalline & 37,40 \\
\hline
\end{tabular}

The feature of crystallinity was influenced by different types of degradation mechanism, such as oxidation and hydrolysis. It increases the intensity of the $\mathrm{C}=\mathrm{O}$ band, especially in the sample dating from the $15^{\text {th }}$ centuries (Fig. $2 \mathrm{~A}_{5}$ ). This could be justified by the presence of a large and intense absorption band between $1650-1732 \mathrm{~cm}^{-1}$ ascribed to the stretching vibration of the $\mathrm{C}=\mathrm{O}$ group, informing on the pronounced alteration $19,37,38,44$. As can be illustrated in Fig 3, the opening chain which is the result of oxidation mechanism occurred on cellulose can be undergoing to the other types of oxidation resulting in another type of compound. 


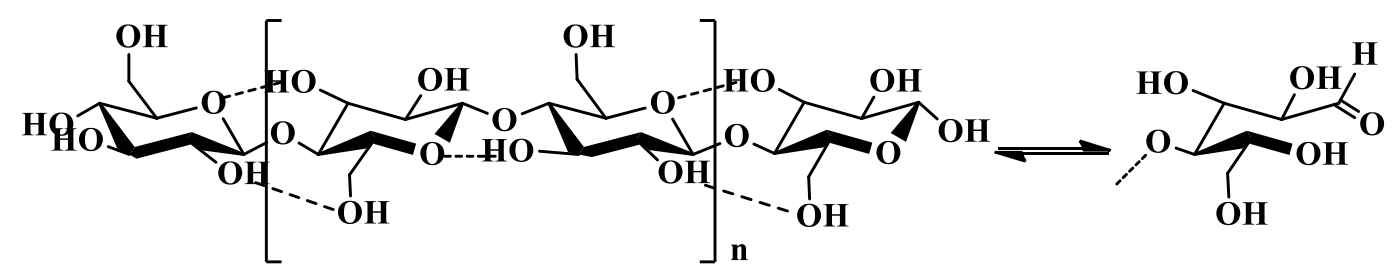

Figure 3. Structure of cellulose $\left(\mathrm{C}_{6} \mathrm{H}_{10} \mathrm{O}_{5}\right)_{n}$ polymer adapted from Fengel and Wegener ${ }^{45}$ (the repeating cellobiose unit is evidenced within the square brackets).

According to Agarwal et al. ${ }^{16}$, the presence of lignin and hemicelluloses influences the amount of the crystalline form of cellulose fibers, and the lignin fraction is the most responsible for this evolution. The presence of the later fraction in all spectra (Fig. 2) is manifested by the following absorptions bands at 1595 and $1504 \mathrm{~cm}^{-1}$ assigned to the $\mathrm{rC}=\mathrm{C}_{\mathrm{ar}}$ skeletal vibration in the phenolic ring (lignin motif type guaiacyl, ie coniferyl) and at $1236 \mathrm{~cm}^{-1}$ attributed to $\mathrm{rC}_{\mathrm{ar}}-\mathrm{O}$ in lignin $27,37,38$. Generally, a weak $1595 \mathrm{~cm}^{-1}$ band stands for non-polar aromatic compounds, while a strong one stands for polar aromatic compounds such as phenols ${ }^{27,38,46}$. In our case study, the very strong $1595 \mathrm{~cm}^{-1}$ absorption indicates well the presence of high polar aromatic compounds of lignin (aromatic ring substituted by hydroxyl and/or methoxy groups : guaiacyl, ie conifer). The obtained result showed an excellent correlation with FT-Raman data (next section).

The small sharp detected at $897 \mathrm{~cm}^{-1}$ (Fig. 2) represents the glycosidic $\mathrm{C}_{1}-\mathrm{H}$ deformation with ring vibration contribution, which is characteristic of $\beta(1-4)$ glycosidic linkages between glucose in amorphous cellulose $14,16,19,27,37,40$. According to $\mathrm{S}$. Acharya et al. ${ }^{39}$, the ratio of integrated peaks at 1427 and $899 \mathrm{~cm}^{-1}\left(\mathrm{~A}_{1427} / \mathrm{A}_{899}\right)$ has been used in order to estimate the IR empirical crystallinity index of cellulose, while in recent study conducted by 22 various IR peak ratios have been proposed using the three following ratios $\left(\mathrm{A}_{1372} / \mathrm{A}_{895}, \mathrm{~A}_{1430} / \mathrm{A}_{894}\right.$, $\left.A_{1372} / A_{2900}\right)$. It should be noted that the amorphous area of the cellulosic component was less affected by the degradation process. According to Boukir et al. ${ }^{46}$ and Zghari et al. ${ }^{37}$, the broad signal at 650 was attributed to $\mathrm{OH}$ out of plane bending ${ }^{10,27,39,40}$.

\section{FT-Raman spectroscopy}

The FT-Raman technique was used to obtain more structural information on the hardwood cellulose samples. The FT-Raman spectra of the three samples are illustrated in Fig. 4. The complexity of FT-Raman spectra is due to the presence of many signals related to the cellulose, hemicelluloses and lignin which create a polymeric matter that produce a complex wooden matrix. All
FT-Raman bands assignment related to the analysed materials were summarized in Table 4.

The FT-Raman spectra of cellulosic fibers can be visually divided into three regions (Fig. 4): 3350$2700 \mathrm{~cm}^{-1}, 1750-800 \mathrm{~cm}^{-1}$ and $610-150 \mathrm{~cm}^{-1}$ that include, respectively, methyl and methylene stretching vibrations, methyl bending and rocking as well as $\mathrm{C}-\mathrm{O}-\mathrm{H}$ in-plane bending and the skeletal bending vibrations (e.g. C-C-C, C-O-C, O-C-C and $\mathrm{O}-\mathrm{C}-\mathrm{O})^{47,48}$.

The broad $\mathrm{CH}$ stretching vibration band at 2897 $\mathrm{cm}^{-1}$ characterize the $\mathrm{CH}_{2}$ group in the glucopyranose ring of cellulose $I_{\beta}{ }^{10}$. The doublet band at $1094 \mathrm{~cm}^{-1}$ and $1119 \mathrm{~cm}^{-1}$ were assigned to the symmetric and asymmetric $\beta$-(1,4)-glycosidic linkage stretching modes, respectively ${ }^{47,49}$. The intensity ratio between these later provides information on the hydrolytic cleavage of the glycosidic ether bonds of the cellulosic chains. According to Kavkler and Demsar 50 , this ratio can be used as an indicator of ageing in different historic specimens. While, the disappearance of these two bands is a sign on an advance cellulose degradation step ${ }^{51}$. In recent literature studies, Ling et al. $2019^{22}$, Makarem et al. $2019^{52}$ and Agarwal et al. $2016^{53}$ reported that the regression of the two main bands at $1096 \mathrm{~cm}^{-1}$ (fingerprint cellulose: broad and very intense) and $2900 \mathrm{~cm}^{-1}$ is an indication on the distortion of crystalline arrangements, and thus, resulting a reduction of Cr.I.. The same trends have been shown in our samples from recent $\left(A_{r}\right)$ to aged one $\left(A_{4}\right)$ but more pronounced until the disappearance of all the bands in the case of very aged one $\left(\mathrm{A}_{5}\right)$, confirming well the complete deterioration of cellulose (Fig. 4). Additionally, the amorphous cellulose fraction is detected in the Raman spectra by the presence of the following signals at $1455 \mathrm{~cm}^{-122,47}$ assigned to $\mathrm{H}-\mathrm{C}$ $\mathrm{H}$ bending with the contribution of smaa 11 proportion of $\mathrm{H}-\mathrm{OC}$ bending, and at $896 \mathrm{~cm}^{-1}$ ascribed to the $\mathrm{C}-\mathrm{H}$ deformation ${ }^{47}$. The two latter signals (amorphous content) influenced by the degradation phenomena underwent the same fate such others absorption bands (1096, $2900 \mathrm{~cm}^{-1}$ ). 


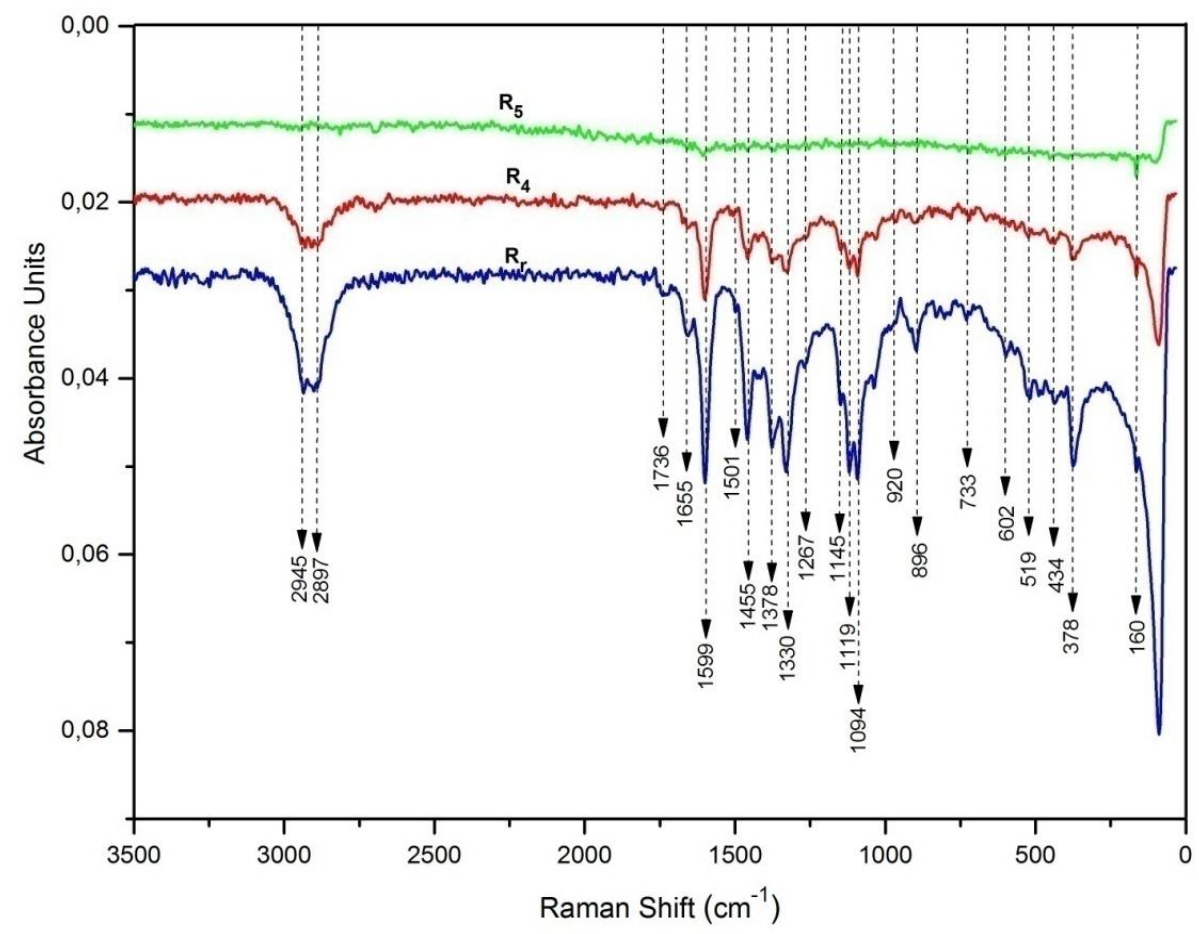

Figure 4. FT-Raman spectra $3500-0 \mathrm{~cm}^{-1}$ range acquired from hardwood samples.

The detected absorptions between 1300 and $1410 \mathrm{~cm}^{-1}$ were characteristic of $\delta \mathrm{CH}_{2}$ modes. Generally, the bands at 1476,1455 and $431 \mathrm{~cm}^{-1}$ (bending $\delta \mathrm{CCO}$ and $\delta \mathrm{CCC}$ ) are typical for crystalline cellulose $\mathrm{I}^{50}$. The arising peak at $519 \mathrm{~cm}^{-1}$ informs on the presence of glycosidic linkage deformation in hemicelluloses $(\delta \mathrm{COC}, \delta \mathrm{CCC})$. The decrease in the intensities of these bands ascribed to loss of the structural order when interchain hydrogen bonds are broken, followed by the cleavage of glycosidic linkages that shortened chains, leading to the decrease of crystallinity depending on the prolonged sample age. The results obtained by FTraman seem to be in complete agreement with the crystallinity index values measured in XRD section (X-ray diffraction, Table 2) and match well with those of FTIR data (FTIR spectroscopy section).

Table 4. Main bands vibrations in hardwood cellulose samples FT-Raman spectra.

\begin{tabular}{|c|c|c|c|}
\hline $\begin{array}{l}\text { Wavenumber } \\
\qquad\left(\mathrm{cm}^{-1}\right)\end{array}$ & Assignments & Fraction & References \\
\hline 2897 & $\mathrm{vCH}$ and $\mathrm{vCH}_{2}$ & cellulose $\mathrm{I} \beta$ & $22,47,52,53$ \\
\hline $1455-1462$ & $\begin{array}{c}\mathrm{HCH} \text { bending and small proportion of HOC } \\
\text { bending }\end{array}$ & $\begin{array}{l}\text { amorphous } \\
\text { cellulose }\end{array}$ & $22,47,51,54$ \\
\hline 1378 & $\mathrm{CH}_{2}$ wagging mode & & 47,55 \\
\hline $\begin{array}{c}1331+1119+990 \\
+\end{array}$ & $\begin{array}{l}\text { bending vibrations of cellulose glycosidic } \\
\text { linkages and/or } \\
\text { Coupled C-O-C and CC stretching modes }\end{array}$ & $\begin{array}{l}\text { amorphous } \\
\text { cellulose }\end{array}$ & $\begin{array}{l}22,10,47,51 \\
55\end{array}$ \\
\hline 1094 & Coupled C-O-C and CC stretching modes & crystalline cellulose & $\begin{array}{c}22,52,53,47 \\
10,51,55\end{array}$ \\
\hline 896 & $\mathrm{CH}$ deformation & $\begin{array}{l}\text { amorphous } \\
\text { cellulose }\end{array}$ & 47,51 \\
\hline 763 & $\beta$-anomer glucopyranose (very weak band) & & \\
\hline 519 & CCO deformations of $\beta$-anomer glucopyranose & cellulose & 55 \\
\hline 431 & $\delta(\mathrm{CCO})$ & crystalline cellulose & 54 \\
\hline 378 & $\begin{array}{l}\text { symmetric bending vibration of pyranose rings } \\
\text { and/or } \delta_{\mathrm{s}}(\mathrm{CCC})\end{array}$ & crystalline cellulose & $\begin{array}{c}22,52,53,47 \\
51,54\end{array}$ \\
\hline
\end{tabular}

It is noteworthy that the evolution of cellulose crystallinity was influenced by the presence of amorphous content, such as lignin and hemicelluloses. In our spectra, this can be confirmed by the typical bands at 1655,1599 and $1267 \mathrm{~cm}^{-1}$ that correspond, respectively, to the conjugated $\mathrm{C}=\mathrm{C}$ 
stretching vibration of coniferyl alcohol (guaiacyl) overlapping with $\mathrm{vC}=\mathrm{O}$ group of coniferyl acid after alcohol oxidation in side chain, and with polar aromatic $\mathrm{C}=\mathrm{C}$ in phenolic compounds related to guaiacyl and syringyl monomers in lignin ${ }^{10,47}$.

The region bands between 300 and $600 \mathrm{~cm}^{-1}$ cannot be unambiguously attributed to certain vibrations, and might be assigned to $\delta \mathrm{C}-\mathrm{C}-\mathrm{C}$ deformation in crystalline fraction of cellulose $22,47,50$, ${ }^{52-55}$, while Dudek et al. ${ }^{55}$ have considered this region as a key of the information and signature of the absolute configuration of the anomeric centre of glycosidic sugar.

\section{Conclusion}

The present work developed a detailed evaluation of cellulose structure as a component of Moroccan hardwood materials as well as the changes that occur at its microcrystalline fraction. Based on the X-ray diffraction obtained results, the cellulose lost its property of crystallinity during exposure time to the natural degradation process. The FTIR spectroscopy and FT-Raman results converge towards the conclusion that the evolution of cellulose crystallinity was influenced by the presence of lignin and hemicelluloses. The used methods were considered as ones of the best vibrational techniques that can be applicable to analyze cellulose polymorphs and evaluate, exhaustively, crystallinity behaviors as well as structural changes on other wood components as lignin and hemicelluloses.

\section{Acknowledgement}

The authors would like to thank Professor P. Doumenq and Dr L. Asia (Aix-Marseille University, Laboratory of Environment Chemistry, Aix en Provence Cedex 4, France) for recording the FT-IR spectra.

\section{References}

1- Y. B. Park, K. Kafle, C. M. Lee, D. J. Cosgrove, S. H. Kim, Does cellulose II exist in native alga cell walls? Cellulose structure of Derbesia cell walls studied with SFG, IR and XRD, Cellulose, 2015, 22, 3531-3540.

2- P. K. Gupta, V. Uniyal, S. Naithani, Polymorphic transformation of cellulose I to cellulose II by alkali pretreatment and urea as an additive, Carbohydr. Polym., 2013, 94, 843-849.

3- L. Donaldson, B. Nanayakkara, J. Harrington, Wood Growth and Development; Elsevier, Encyclopedia of Applied Plant Sciences (Second Edition), 2017, 1, pp. 203-210.

4- Y. Kataoka and T. Kondo, FT-IR Microscopic Analysis of Changing Cellulose Crystalline Structure during Wood Cell Wall Formation, Macromolecules, 1998, 31, 760-764.
5- H. Kono, S. Yunoki, T. Shikano, M. Fujiwara, T. Erata, M.J. Kawai, CP/MAS ${ }^{13}$ C NMR Study of Cellulose and Cellulose Derivatives. 1. Complete Assignment of the CP/MAS 13C NMR Spectrum of the Native Cellulose, J. Am. Chem. Soc., 2002, 124, 7506-7511.

6- P. Bansal, M. Hall, M.J. Realff, J.H. Lee, A.S. Bommarius, Multivariate statistical analysis of X-ray data from cellulose: a new method to determine degree of crystallinity and predict hydrolysis rates, Bioresour. Technol. 2010, 101, 4461-4471.

7- S. Park, J. O. Baker, M. E. Himmel, P. A. Parilla, D. K. Johnson, Cellulose crystallinity index: Measurement techniques and their impact on interpreting cellulase performance, Biotechnol. Biofuels, 2010, 3, 1-10.

8- S.P.S. Chundawat, G. Bellesia, N. U. ppugundla, L. da Costa Sousa, D. Gao, A. M. Cheh, U. P. Agarwal, C. M. Bianchetti, G. N. Phillips, P. Langan, V. Balan, S. Gnanakaran, B. E. Dale, Restructuring the crystalline cellulose hydrogen bond network enhances its depolymerization rate, J. Am. Chem. Soc., 2011, 133, 11163- 11174.

9- J. Zhang, Y. Wang, L. Zhang, R. Zhang, G. Liu, G. Cheng, Understanding changes in cellulose crystalline structure of lignocellulosic biomass during ionic liquid pretreatment by XRD, Bioresour. Technol., 2014, 1 51, 402405.

10- A.L. Barnette, C. Lee, L.C. Bradley, E.P. Schreiner, Y.B. Park, H. Shin, D.J. Cosgrove, S. Park, S.H. Kim, Quantification of crystalline cellulose in lignocellulosic biomass using sum frequency generation (SFG) vibration spectroscopy and comparison with other analytical methods, Carbohyd. Polym. 2012, 89, 802-809.

11- Z.H. Jiang, Z. Yang, C. L. So, C. Y. Hse, Rapid prediction of wood crystallinity in Pinus elliotiiplantation wood by near-infrared spectroscopy, J. Wood. Sci., 2007, 53, 449-453.

12- K. Labidi, O. Korhonen, M. Zrida, A. H. Hamzaoui, T. Budtova, All-cellulose composites from alfa and wood fibers, Ind. Crops. Prod., 2019, 127, 135-141.

13- D. Ciolacu, F. Ciolacu, V. I. Popa, Amorphous cellulose- structure and characterization, Cell. Chem. Technol., 2011, 45, 13-21.

14- D. Tamburini, J. J. Łucejko, M. Zborowska, F. Modugno, E. Cantisani, M. Mamonov, M. P. Colombini, The short-term degradation of cellulosic pulp in lake water and peat soil: A multi-analytical study from the micro to the molecular level, Int. Biodeterior. Biodegradation, 2017, 116, 243-259.

15- F. Lionetto, R. D. Sole, D. Cannoletta, G. Vasapollo, A. Maffezzoli, Monitoring Wood Degradation during Weathering by cellulose crystallinity, Materials, 2012, 5, 1910-1922. 
16- U. P. Agarwal, S. A. Ralph, R. S. Reiner, C. Baez, new cellulose crystallinity estimation method that differentiates between organized and crystalline phases, Carbohyd. Polym., 2018, 190, 262-270.

17- L. Segal, J.J. Creely, A.E. Martin, C.M. Conrad, An empirical method for estimating the degree of crystallinity of native cellulose using the X-ray diffractometer. Text. Res. J., 1959, 29, 786-794.

18- A. D. French, M. Santiago Cintrón; Cellulose polymorphy, crystallite size, and the segal crystallinity index, Cellulose, 2013, 20, 583-588.

19- L. Hajji, A. Boukir, J. Assouik, A. Kerbal, M. Kajjout, P. Doumenq, M. L. De Carvalho, A Multi-analytical Approach for the Evaluation of the Efficiency of the Conservation-Restoration Treatment of Moroccan Historical Manuscripts dating to $16^{\text {th }}, 17^{\text {th }}$ and $18^{\text {th }}$ centuries, Appl. Spectrosc., 2015, 69, 920-938.

20- S. Nam, A. D. French, B. D. Condon, M. Concha; Segal crystallinity index revisited by the stimulation of X-ray diffraction patterns for cellulose I $\beta$ and cellulose II. Carbohyd. Polym., 2016, 135, 1-9.

21- I. Carrillo-Varela, M. Pereira, R. T. Mendoça; Determination of polymorphic changes in cellulose from Eucalyptus spp. Fibres after alkalization. Cellulose, 2018, 25, 6831-6845.

22- Z. Ling, T. Wang, M. Makarem, M. Santiago Cintrón; S. Nam, J. V. Edwards, S. H. Kim, F. Xu, A. D. French; Effects of ball milling on the structure of cotton cellulose. Cellulose, 2019, 26, 305-328.

23- P. Scherrer, Bistimmung der GroBe und der inneren Structur von kolloidteilchen mittels rontgenstrahlen. Nachrichten von der Gesellschaft der Wissenschaften zu Gottingen, 1918, 26, 98-100.

24- H.L. Chen, A. Yokochi, X-Ray Diffractometric Study of Microcrystallite Size of Naturally Colored Cotton J. Appl. Polym. Sci., 2000, 76, 1469.

25- X. Ju, M. Bowden, E. E. Brown, X. Zhang, An improved X-ray diffraction method for cellulose crystallinity measurement, Carbohyd. Polym., 2015, 123, 476-48.

26- M. Danish, R. Hashim, M.N. Mohamad Ibrahim, M. Rafatullah, O. Sulaiman, Surface characterization and comparative adsorption properties of $\mathrm{Cr}(\mathrm{VI})$ on pyrolysed adsorbents of Acacia mangium wood and Phoenix dactylifera L. stone carbon. J. Anal. Appl. Pyrol., 2012, 97, 19-28.

27- A. Boukir, S. Fellak, P. Doumenq, Structural Characterization of Argania Spinosa Moroccan Wooden Artifacts during natural degradation progress using Infrared Spectroscopy (ATRFTIR), X-Ray Diffraction (XRD) and
Scanning Electron Microscopy (SEM), Heliyon, 2019 (under revision).

28- A. D. French; Idealized powder diffraction patterns for cellulose polymorphs. Cellulose, 2014, 21, 885-896.

29- E. L. Hult, T. Iversen, J. Sugiyama, Characterization of the supermolecular structure of cellulose in wood pulp fibres. Cellulose, 2003, 10, 103-110.

30- J.V. Edwards, K. Fontenot, F. Liebner, N. Doyle nee Pircher, A. D. French, B.D. Condon.; Structure/Function Analysis of Cotton-Based Peptide-Cellulose Conjugates: Spatiotemporal/Kinetic Assessment of Protease Aerogels Compared to Nanocrystalline and Paper Cellulose. Int. J. Mol. Sci. 2018; 19, 840.

31- R. M. Rowell, R. Pettersen, J. S. Han, J. S. Rowell, M.A., Tshabalala, Cell wall chemistry. In: Rowell, R.M. (Ed.), Handbook of Wood Chemistry and Wood Composites. CRC, Boca Raton, London, New York, Singapore, 2005, pp. 37-76.

32- R. Shimura, A. Nishioka, I. Kano, T. Koda, T. Nishio, Novel method for producing amorphous cellulose only by milling, Carbohyd. Polym., 2014, 102, 645-648.

33- C. M. Popescu, M. C. Popescu, C. Vasile, Structural changes in biodegraded lime wood, Carbohyd. Polym., 2010, 79, 362-372.

34- U. J. Kim, S. Kuga, M. Wada, T. Okano, T. Kondo, Periodate oxidation of crystalline cellulose, Biomacromolecules, 2000, 1, 488-492.

35- J. Rojas, V. Kumar, Effect of polymorphic form on the functional properties of cellulose: A comparative study, Carbohyd. Polym., 2012, 87, 2223-2230.

36- M. C. I. Mohd Amin, A. G. Abadi, H. Katas, Purification, characterization and comparative studies of spray- dried bacterial cellulose microparticles, Carbohyd. Polym., 2014, 99, 180-189.

37- B. Zghari, L. Hajji, A. Boukir, Effect of Moist and Dry Heat Weathering Conditions on Cellulose Degradation of Historical Manuscripts exposed to Accelerated Ageing: ${ }^{13} \mathrm{C}$ NMR and FTIR Spectroscopy as a nonInvasive Monitoring Approach. J. Mater. Environ. Sci., 2018, 9, 641-654.

38- C. M. Popescu, P. Gradinariu, M. C. Popescu, by white rot fungi through infrared and twodimensional correlation spectroscopy, J. Mol. Struct., 2016, 1124, 78-84.

39- S. Acharya, Y. Hu, H. Moussa, N. Abidi, Preparation and characterization of transparent cellulose films using an improved cellulose dissolution process. J. Appl. Polym. Sci., 2017, 134, 44871.DOI: 10.1002/APP.44871.

40- M. Schwanninger, J. C. Rodrigues, H. Pereira, B. Hinterstoisser, Effects of short-time vibratory ball milling on the shape of FT-IR 
spectra of wood and cellulose, Vib. Spectrosc., 2004, 36, 23-40.

41- M. Broda, C. M. Popescu, The natural decay of archaeological oak wood versus artificial degradation processes: an FT-IR spectroscopy and X-ray diffraction study, Spectrochim. Acta Part A: Mol. Biomol. Spectro., 2019, 136, 1038-1046.

42- Y. Song, J. Zhang, X. Zhang, T. Tan, The correlation between cellulose allomorphs (I and II) and conversion after removal of hemicellulose and lignin of lignocellulose. Bioresour. Technol., 2015, 193, 164-170.

43- N. Abidi, L. Cabrales, C.H. Haigler, Changes in the cell wall and cellulose content of developing cotton fibers investigated by FTIR spectroscopy. Carbohyd. Polym., 2014, 100, 9-16.

44- L. Hajji, A. Boukir, J. Assouik, S. Pessanha, M. L. De Carvalho, Artificial ageing paper to assess long term effects of conservative treatment. Monitoring by Infrared spectroscopy (ATR-FTIR), X-ray diffraction (XRD) and Energy dispersive X-ray fluorescence (EDXRF), Microchem. J., 2016, 124, 646-656.

45- D. Fengel and G. Wegener, Wood, Chemistry, Ultrastructure, Reactions. Waster \& Grugter, New York, 1984, pp: 613.

46- A. Boukir, M. Guiliano, L. Asia, G. Mille, A fraction to fraction study of photooxidation of BAL 150 crude oil asphaltenes, Analusis, 1998, 26, 358-364.

47- S. Fellak, A. Boukir, Moroccan Cedar softwood study: Application of FT-Raman spectroscopy, MATEC Web. Conf., 2018, 191, 00014. https://doi.org/10.1051/matecconf/2018191000 14.
48- Y. Essaadaoui, A. Lebkiri, EL H. Rifi, L. Kadiri, A. Ouass, Adsorption of cobalt from aqueous solutions onto Bark of Eucalyptus. Mediterr. J. Chem., 2018, 7, 145-155.

49- K. Schenzel, S. Fischer, NIR FT Raman Spectroscopy: A rapid analytical tool for detecting the transformation of cellulose polymorphs, Cellulose, 2001, 8, 49-57.

50- K. Kavkler, A. Demsar, Examination of cellulose textile fibres in historical objects by micro-Raman spectroscopy, Spectrochim. Acta Part A: Mol. Biomol. Spectro., 2011, 78, 740-746.

51- M. Petrou, H.G. M. Edwards, R.C. Janaway, G.B. Thompson, A.S. Wilson, Fouriertransform Raman spectroscopic study of a Neolithic waterlogged wood assemblage, Anal. Bioanal. Chem., 2009, 395, 2131-2138.

52- M. Makarem, CM, Lee, K. Kafle, S. Huang, I. Chae, H. Yang, J.D. Kubicki, S.H. Kim, Probing cellulose structures with vibrational spectroscopy, Cellulose, 2019, 26, 35-79.

53- U. P. Agarwal, S. A. Ralph, R. S. Reiner, C. Baez, Probing crystallinity of never-dried wood cellulose with Raman spectroscopy, Cellulose, 2016, 23, 125-144.

54- N. Gierlinger, S. Luss, C. Konig, J. Konnerth, M. Eder, P. Fratzl, Cellulose microfibril orientation of Picea abies and its variability at the micron-level determined by Raman imaging, J. Exp. Bot., 2010, 61, 587-595.

55- M. Dudek, G. Zajac, E. Szafraniec, E. Wiercigroch, S. Tott, K. Malek, A. Kaczor, M. Baranska, Raman Optical Activity and Raman spectroscopy of carbohydrates in solution, Spectrochim. Acta Part A: Mol. Biomol. Spectro., 2019, 206, 597-612. 